\title{
A Social E-Learning Experience in the Raval Neighbourhood: Human Perceptions and Community Development
}

\author{
Ann Amat, MA. \\ Dept. Social and Systematic Pedagogy \\ Autonomous University of Barcelona \\ anamatrico@gmail.com
}

Isabel Alvarez, $\mathrm{PhD}$. (Corresponding author)

Dept. Social and Systematic Pedagogy

Building G6, 08193 Bellaterra (Cerdanyola del Vallès), Barcelona, Spain Tel:

1-34-93-581-1411 E-mail: Isabel.alvarez@uab.cat

Received: December 14, 2016 Accepted: December 27, 2016 Published: December 29, 2016

doi:10.5296/ire.v5i1.10455 URL: http://dx.doi.org/10.5296/ire.v5i1.10455

\begin{abstract}
The aim of this study is based on the analysis of a socio-educational programme, from a relational and real-life perspective, enriched by John Dewey's Theory concerning experiences of aesthetic quality. The e-learning is an omnia point located in the Raval neighbourhood in Barcelona, Spain. The methodology is qualitative and interpretative, and concentrates on the study of one particular case, with in-depth interviews with key contributors. The results obtained underline the importance of the study as regards the promotion, creation and consolidation of human relationships, networking and, consequently, the personal development of the participants. Finally, the conclusions presented are related to the community experiences of aesthetic quality, particularly insofar as they impinge on interpersonal relationships, their influence on learning, each association's connections with the community and networking as a means of communication among all the associations in the neighbourhood, which makes it possible to organise socio-cultural events in which all the residents in the neighbourhood are given a voice, thus promoting the development of
\end{abstract}


community.

Keywords: "Omnia points", social e-learning programmes, social inclusion, work and community work and development, e-learning and experiences with aesthetic quality.

\section{Introduction}

This study reflects on the influence of the social e-learning programme "Punt Òmnia" (Note 1), located in the premises of the Young People's Association (TEB) (Note 2) in the Raval neighbourhood, and in particular it focuses on perception of social experiences that this programme generates both individually and within the community as a whole. Thus, given this specific focus of attention, the study sets out to observe, interpret, analyse and improve the aforementioned e-learning programme from the point of view of those who are directly involved in it (providers, users and the residents of the neighbourhood), in the light of their own perceptions of the experiences that it offers. This influence is measured in terms of the experiences of aesthetic quality of the people who comprise this community. These experiences, according to Dewey (1934), are unique, and enable us to learn, grow, and develop, and offer us fulfilment and satisfaction. Art and the aesthetic are not only to be found in visual or creative experiences, but they are an integral part of our daily lives, of social experiences, of all our actions and interactions conducted in such a way that our perception directs the experience towards the goal of satisfaction, fulfilment and development. They are experiences which we remember in detail because they are the experiences by which our lives are nourished, and become an art form.

This social e-learning programme was conceived with the intention in mind of reducing the inequalities involved in gaining access to and using the ICT tools required to gain digital competence and skill. For this reason it is of the utmost importance to assess the perception that the community has, and the initiatives that are being generated. The study arises out of a personal desire to carry out an in-depth, qualitative investigation, by getting to know the contributors and interacting with them all, fairly and democratically, with a view to understanding the value of the service that this entity is providing. In other words, the main motivation in conducting this study lies in the fact that it evaluates a social service in a qualitative manner, on the basis of the perceptions of the people involved.

For this reason, it arises out of the importance that the research attributes to these socio-economic programmes developed within a neighbourhood that is characterised by intercultural and intergenerational cohabitation. It is a neighbourhood that has undergone a number of highly significant changes in recent years, and where, thanks to the community based socio-economic programmes developed by different (charitable) entities and associations, and networking, which have taken shape over the years, a social/community service is being offered to the local inhabitants in every aspect of their lives, and thus improving the quality of their lives. In a world like ours, where information technology is transforming social relationship, and also requirements in relation to entry into the labour market, which are increasingly specific and have more and more to do with digital skills, a great deal of work remains to be done to reduce the many social inequalities, especially in contexts where they are particularly visible. 


\section{Context}

The study focuses one of the Omnia Points located in the Raval, a neighbourhood that forms part of the historic centre of Barcelona, in the part of the city known as the Old City, and where the largest proportion of people at risk of social exclusion is concentrated. It would be worth exploring, according to Obando (2007), whether the residents' physical networks are undergoing a process of mimetic adaptation characteristic of those who have access to modern technologies and are therefore magnifying the differences between the various cultures that share the same territory. In this territory, where the speed with which things are happening is making it necessary for people with needs in common to come together, be it to find a job, or to rent a room or a flat through Internet, among other things, it is indispensable to examine in greater detail the transformations of these community settings in which these information and communication technologies have been instrumental. It is in this context, then, that one of the Omnia Points, located in the TEB Association of Young People, has taken shape, and it is this Omnia Point that constitutes the justification of the present study.

This e-learning programme has been accessible to the community since 1999, even though it has adapted to changing circumstances with the passing of time (it is the pioneer entity in terms of access to, and more specifically, of the design and implementation of this programme). All this makes the programme acutely relevant and makes this Young People's Association particularly suitable for the study. Besides, it is one of the entities working in the neighbourhood with the highest level of socio-educational activity, and it is dynamic and very receptive to suggestions from within the community. For this reason it has received many awards during its trajectory for the social work that it has carried out in the neighbourhood. Its success can partly be attributed to the importance it gives to its participants, as it is an entity which was born among and is nourished by young people in the neighbourhood. Therefore most people who participate in the TEB are people who face the risk of social exclusion, and represent a wide diversity of users, both in terms of their personal circumstances and their origin. Despite being open to participation from all citizens, it is users of this kind who are most likely to access community services, due to their lack of resources.

On the other hand, there are differences within the sector of the population participating in the association, in terms of the continuity or discontinuity of their involvement in the activities. There is a group of people who are very assiduously involved, as they have formed relational and affective bonds with the association and with the professionals who work in it. Nevertheless, there is also a larger group of (young) people who take part sporadically in the association's activities, whether because of a change of address, of their sporadic availability or personal interest.

The "Omnia Point" social e-learning programme, is a formative, preventive and socio-educational programme, based on access to and use of information and communication technologies. It is formative because it sets out to provide technological training for its users, in terms of practical functionality for their everyday lives. It is preventive in the sense that it serves to prevent and reduce the digital gap that might exist between those who have access 
to Internet, and those who do not, and to prevent the recurrence of existing inequalities. Finally, it is regarded as socio-educational in that it is integrated into a series of institutional interventions aimed at providing education outside the formal educational system.

Thus, the aim of the omnia initiative is to offer physical spaces and ICT installations, namely the aforementioned Omnia Points, with the support of a professional who motivates, trains and assesses the people who uses this point. The role of the local coordinator consists mainly in developing the programme in each territory and turning each Omnia into: 1) a space where participants are made welcome (knowledge of the community: its language and culture), 2) an information centre (about community initiatives, training programmes, administrative procedures and joining the job market), 3) a place of learning (the use of ICT tools, professional and life-skills and autonomy), 4) an opportunity for socialisation (knowing about and creating relational and/or affective bonds) and, finally, 5) an opportunity for participation in the community (bonding with the community, a community spirit, participation in neighbourhood initiatives: traditions, festivals and customs). This is the view of one of the facilitators (Coordinator 2):

The philosophy (of the Omnia Point) ... is to learn how to use the tools, not only to write a curriculum vitae and send it, ... but to use the network as a social space ... also a way of improving communication and building community ..., it's about seeing the Omnia point not only the four or five computers but also working with tablets and smart-phones and other devices.... And understanding that people are more connected than ten years ago, and maybe the things they see around them are different ... and simply being aware and acting accordingly.

Therefore, we can see that this Omnia point in particular has evolved a great deal since it was created. Just as the users of the programme have diversified in the course of time, so the programme itself has seen many variations, from basic technological training for non-digital-natives to specific activities like producing videos and images, sound-recording, always on the basis of the needs and interests of the users off the point. In this way, we have reached the point where the TEB Omnia point is so rooted in the association that it functions as a meeting point; that is to say, most of the activities which arise out of the TEB do so through this programme, which serves as a vertebral and transversal axis for all the proposals put forward by the users.

\section{Theory: Perceptions and Experiences of Aesthetic Quality}

What interests us about this community is to find out about the social perceptions (experiences with technology, Cilesiz, 2011; player's affective body expressions, Savva, 2012; in adult education, Clover et al., 2013; environmental aesthetics, Kholina, 2015;), both individual and collective, around the e-learning training programme in question. Gonzalez (2006) defines the perception as part of the perceptive process which organises and interprets the information, assigning to it the meaning picked up by the sense organs (Abbs, 1989), thus enabling the recognition of meanings, objects and events. Readman and Wise (2004) add the centrality of experiential learning, where teachers and students working as co-artists. This part of the perceptive process allows us to construct our perceptions on the basis of previous 
experiences and expectations in relation to the situation or object being perceived.

Perception in this study is closely linked to previous experiences and to expectations; that is to say, it is a personal and collective construction concerning a specific object, such as the social e-learning programme, on the basis of the expectations that one has before acting, and of the aesthetic quality experiences that this programme imparts to the users of the e-learning training programme. By this definition of perception it is inseparably bound up with interpretation, which should be understood as a combination of perceptual predisposition and the effect of context, so that a single stimulus can trigger different perceptions, depending on the differences between our frameworks, but also differences of context (in this regard researchers should always be aware of this aspect of our intersubjectivity as they seek to understand individual's perceptions about their experiences (Bliss, 2016).

Thus, just as the perceptions of the different participants in the socio-educational programme in question vary from person to person, so not everyone interprets the same situation in the same terms, in spite of the fact that the immediate context is the same. This is the case because the previous experiences of the participants also comes into play, as do the expectations that they had in relation to the socio-educational programme, and their specific personal circumstances. So, as the experiences which the programme offers are personal, and not everyone views it in the same way, they are not experiences of aesthetic quality for everybody. When this philosophical concept is transferred to Dewey's pedagogy (1934), it adds to the definition of experience the ability of an experience to enhance the inner personal growth of the individual, and the shaping of his or her social identity. According to Rodriguez (2004), it is only aesthetic quality that gives meaning to what we experience, as it is only through aesthetic experience (everything depends on a specific time and place) that an immediate and, to some extent, conscious cooperation occurs between our organism and the (physical or human) surroundings or context; aesthetic quality permeates our activity with an illuminating and irrepressible meaning (Dewey, 1934).

This study explores the perception of these experiences of aesthetic quality as they are experiences which enrich the lives of the participants in the programme, contribute to their personal development at every level, especially to the shaping of their social and com 2 munity identity, which is one of the aims of the programme under consideration (Is like "being together in a particular way", Green (1995) and Smith, (2016). It is important to notice the perspective from which the concepts of perception and experience are addressed. In this study both concepts form part of the same construct; that is to say, experience cannot be understood in isolation from one's perception of oneself, and perception is, by definition, whichever senses are involved, an experience in its own right. In this sense, perceiving can be understood as experiencing a situation or an object. This is a philosophical and constructivist perspective (Dewey, 1934: 21-23), as the author unites both concepts in a single concept, so that interdependent processes are at work, "In order to perceive, a perceiver must create his own experience" Dewey (1934: 62); perception is necessary to achieve an experience of aesthetic quality, and is to be understood here as a phase of experience, a necessary and indeed indispensable one in order for an experience to be an aesthetic one. Nevertheless, they could be interpreted as interwoven processes, as throughout his book (Dewey, 1934) the 
author uses the terms "aesthetic perception" and "aesthetic experience" interchangeably. "It was at times of the most intense aesthetic perception that Keats found his greatest pleasure, and his deepest convictions" Dewey (1934: 39-40).

In the same way, our view is that perception forms part of experience, in that it marks the difference between an experience and an aesthetic experience. Thus, in this study, participant data are extracted relating to the perception of the experiences of aesthetic quality which the e-learning programme provides, in the light of our understanding that there is no experience without perception. In this way, the two sides of the coin become apparent, and a very valuable coin it is too. As aesthetic experience is vital, conscious and active, it is the path that leads to development, and, most importantly, it brings us satisfaction and absorption (when we are completely enganged by something and thinking of nothing else except that in which one is absorbed (Diessner et al., 2016)). This discovery is what leads us to seek this source of the satisfaction that results from a connection between active participation and the action (or sensation) that is being experienced. In this way, perception plays the leading role in the person who is having an experience, so it is fair to say that perceiving is equivalent to the creation of an aesthetic experience, and but for this perception the creation of experiences of aesthetic quality would not be possible.

In so far as the development of an experience is controlled by means of reference to these relationships of order and satisfaction, which are felt immediately, this experience assumes a predominantly aesthetic character. The action drive becomes the drive towards the type of action which results in an object that gives satisfaction in the direct perception of it. Dewey (1934: 58)

This aesthetic theory of Dewey's, which corresponds to the philosophy of art, aims to bring art closer to daily life, not forcibly, but by going back to the origins, when art formed part of people's everyday lives. We have lost our connection with art and aesthetic experiences, as such experiences do not only arise from what were regarded as objects of art, but, in so far as they produce experiences, are also the events and scenes from daily life which attract the eye and the ear of people, arousing their interest and inducing satisfaction while they watch or listen, and those social situations which catch people's attention, such as a fire engine passing at top speed, an argument between two people in a public square, the embrace of two lovers, climbing a mountain, among millions of other everyday situations which could be considered aesthetic, provided that someone experiences them as aesthetic, and they reach their culmination and contribute to personal development.

Recovering the continuity of aesthetic experience with reference to the normal processes of life. The understanding of art and of its role in civilisation, (...) The understanding that the theory proposes will be achieved in the form of a circle: returning to common experience, and surrounding things so as to discover the aesthetic quality that this experience possesses. Dewey (1934: 11-12)

According to Dewey (1934: 12) there are many theories about art, but if there is a reason for this aesthetic philosophy it is because it puts forward another way of approaching the subject. Previous theories presuppose an already established separation, a conception of art which 
"spiritualises" it disconnecting it from the objects of concrete experience. The author's alternative is to discover the path by which these works idealise the qualities that can be found in common experience. "If the works of art were placed directly within a human context, easily accessible to ordinary people, they would have a much broader appeal than is possible under theories which present art as something that is ethereal and beyond most people's reach." (Dewey, 1934: 12). Everything that we now consign to our museums, used to be the means whereby the processes of everyday life were exalted: "They belonged to a display of prowess, the manifestation of group and class membership, worship of gods, feasting and fasting, fighting and hunting and all the rhythmic crises that punctuate the stream of living" (Dewey, 1934: 7).

So aesthetic experience essentially means the experience of satisfaction which reaches its culmination, an integrated experience which is intrinsically worthwhile. According to Claramonte: "they cannot be conceived of as formalised demonstrations o modes of relationship, given that the aesthetic experience is the apprehension, the lived experience of those modes of relationship, and the ways in which we incorporate them into our everyday lives." in the prologue of Dewey, 1934: XVIII). These experiences increase our capacity to act and to understand, the agency (Note 3) of our modes of relationship. In present-day society, where the market has invaded every area of everyday life, and has separated aesthetic experience from ordinary experience, it is necessary to stress all the more strongly the extent to which aesthetic experience, as experience, is common to everyone, and is absolutely essential, as they are experiences which enable us to enjoy life, which are a source of satisfaction, and which make it possible to learn from and modify our actions, our thoughts and the types of relationship we engage in. Even so, not all experiences of aesthetic quality offer immediate satisfaction, though that does not disqualify them as such experiences; there are experiences which are characterised by sadness or loss, for example, and yet they can be regarded as experiences of aesthetic quality because we remember them in their entirety, because they have helped us to learn and to develop. Therefore, this study sets out to observe the aesthetic experience as common experience, thus placing aesthetics once again at the heart of everyday social life, and experiences that are shared by the community, as these experiences are essential to social and personal development.

It must be borne in mind that, in the study, the experiences in question are taken from the interviews with the different informers, they are remembered and transmitted differently, and the way in which they are described varies from person to person, and everything expressed as experience by each of the informers is valid, in that it is an experience of that person, even though the description of it may be more or less detailed. Thus, the experiences of aesthetic quality are many, and complete; it's not that they finish, but they reach a fulfilment, they reach an end in the sense of fulfilment, and thus they have a unity which gives them their name, that concert, that beginning of a friendship, etc. This unity constitutes a particular quality (Dewey, 1934) which permeates the whole experience, even though the parts that it is made up of differ from each other. This unity is not emotional, nor practical, nor intellectual, as these terms are distinctions or classifications which the subject makes as they reflect on the experience a posteriori. This unity is made up of adjectives of interpretation, and 
interpretation is always subjective and personal, specific to the person who comes up with it.

\section{Research Methods}

The research has been designed as an in-depth case study (Ying, 2014) of one particular entity, the TEB and the community where it is located, as a specific case in point. Thus, the study is of an interpretative (Wolcott, 1994) character and its methodology is qualitative, in that it sets out to collect information and interpret it from the point of view of the person transmitting the information, that is to say, of three different groups: the users, the organisers and the residents of the neighbourhood.

The aim of the study is to conduct an in-depth exploration and analysis of the phenomena that make up the life-cycle of the unit in question, with a view to gaining a deeper insight into it. In other words, the study's aim is to study and analyse the experiences of aesthetic quality (phenomena) which the omnia point e-learning programme (the chosen unit) generates or has generated (its lie-cycle)

\subsection{Participants}

The strategy used for informing the informers was purposive sampling (Patton, 2015), as it was a qualitative study in a heterogeneous population, which resulted in a further sampling of nine key informers (three for each of the groups involved). This sampling was designed in the course of the research, making use of prior exploration of the context by means of participant observation (Marin, 1985), on the basis of the dimensions of analysis of the study, and the concrete situations of those who could facilitate (or obstruct) the generation of social experiences of aesthetic quality. Likewise, the selection of informers was determined by the principles of pertinence and sufficiency of the information in question. Pertinence, in the sense that the informers could the largest amount of and the best information; sufficiency, in the sense that the information obtained was sufficient to develop a rich and comprehensive description of the phenomenon under investigation (saturation stage).

The key informers selected were divided into three groups in accordance with the nature of their roles, both in the entity and in the community: 1) The facilitators of the omnia point were educators or social workers, whose role was to provide training and orientation. 2) The users were young people attending the TEB as participants in the training, educational and socio-cultural activities. 3) The residents were people who were familiar with the TEB and its activities, but who did not have any reason to be part of it, and who, nevertheless, were residents of the Raval community (the three groups of key informers participated in the Mediateca, an activity that had been designed by several different entities to compile a historical memory of the neighbourhood).

The duration of the study was nine months. For that reason, the criterion of pertinence has been followed in selecting the informers that were interviewed and the criterion of adequacy in focussing on the collective experiences of aesthetic quality, those that are genuinely shared, at least by the community of informers, and therefore it is possible to reach the point of information saturation in experiences, also subjective, of this kind. 
The aim behind this procedure was to complete the research with comprehensive knowledge of the perceptions, the individual and collective experiences of aesthetic quality, the relationships and the influences of the omnia point e-learning programme, since at the beginning of the programme there was no way of knowing how or why the TEB omnia point influenced the community. That is where the need for this study arises from, and it is from this that we can confirm the validity of the methodology chosen, as the interviews help to find relationships, influences and perceptions of the lived experiences, both personal and collective, and the participant observation involves entering the field beforehand in order to understand the entity and the individuals that comprise it so as to divide them into different groups of informers, to find those that are significant for the study, and to choose the aspects that will form the basis on which to design and analyse the interviews for the study.

It was decided to validate the semi-structured personal interviews in the light of the qualitative nature of this tool for the collection of information. This was followed by a validation by experts, and a peer validation or review (Osterlind, 1989). This validation was necessary due to the importance of making sure that the questions would be understood by the key informers (Silverman, 1993).

\subsection{Instruments}

Two main instruments were used. 1) Participant Observation throughout a period of nine months, recorded in the field-work $\log$ and 2) 9 Semi-structured interviews to key participants. These two techniques helped to triangulate the data drawn, in this case, experiences with aesthetic quality.

\subsubsection{Participant Observation}

Entering in such community required to buil-up some rapport over time (in other words the researcher is also a member of the group being observed, Morgan, et al. 2016). One of the researchers was attending the center once a week and systematically observing people in naturally occurring contexts, which could potentially reveal more information than individuals could recall or be aware of (Mays \& Pope, 1995; Morse, 2003; Mulhall, 2003; Morgan et al., 2016). In this study, the data drawn from the observation served as "front seat" for later on decide: 1) Selection criteria for the interviewees and 2) The data drawn from the observation informed individual semi-structured interviews.

\subsubsection{Semi-structured Interviews}

A purposeful sampling helped to select the participants who later one would be the key informants (Friedman, et alii, 2016). The interviews lasted about an hour each and took place whenever the participants agreed according to their own busy lives. The interviews were done face-to-face and happened within the Omnia facilities. All the interviews were digitally recorded, transcribed and coded using in vivo coding (Saldaña, 2013). 


\section{Results}

\subsection{Analysis and Discussion of the Data}

By means of data analysis, it is possible to see which of the categories established for the research (those extracted from participant observation) are obtained for validation by means of the tools used for the collection of information: that is to say, which of them can be used for the analysis of the dimensions and sub-dimensions (more specific expression of the dimensions) considered, and in the event of others being discovered, to add them. In the event of new categories being added, it must be remembered that these categories (or analysis units) should be interpretative adjectives (Dewey, 1934: 43) which refer to the participants themselves in the communication of the experiences of aesthetic quality, and, these categories would be numerous, as each person expresses themselves differently, so the interpretative adjective will be generalised so as to reduce the number of categories and facilitate the reading of the resulting data analysis.

In this article we shall focus our attention on the data extracted from the nine interviews conducted with the key informers in relation to the dimension underlying this study, such as that of human experience and community development. The presentation of the results will be carried out separately with reference to each group of informers, in order subsequently to make it possible to determine the most noteworthy experiences of aesthetic quality across the three groups.

\subsubsection{Facilitators}

As regards integrated personal development, all of them expressed experiences of aesthetic quality in their professional development in different respects, such as: the variety of tasks, coordination and management, pedagogical freedom and the scope they were given to act. They also referred to experiences relating to values, the multi-disciplinary way in which these values were treated, as respect is the entity's only norm. Likewise, they highlighted the reference to human rights as the theme of many of the activities organised under the programme. Some of the experiences expressed also reflected the need to develop social and emotional skills, especially among those who are looking for work.

This group sees the omnia point as a "heaven" for relationship-building and meeting people. As regards interpersonal relationships, the three informers see experiences of aesthetic quality in that there is a friendly working atmosphere among the instructors, and a good sense of equality in their relationship. Despite the lack of communication due to agenda problems, they all fully understand the importance of coherence in the way they act. In the relationships between the different participants, experiences have been observed which can be seen to have had a beneficial effect on the pursuit of learning (they help each other) and on their participation in the activities, and also in the development of bonding with the users, the entity and the community. In the relationships that are established between instructors and participants, there is more diversity as regards the expression and conception of the experiences, but proximity and naturalness can be observed, as well as horizontal (not hierarchical) interaction. These relationships nevertheless do not amount to friendship, but, despite being personal and close, also involve limits being imposed. It is all about seeking a 
balance. They are informal relationships, but within the formal parameters that commitment to the entity and co-responsibility entail.

In relation to the participation in the entity, the experiences of aesthetic quality that have been observed vary depending on the project or activity. For example, in the free use of the omnia space, there have been experiences in which, during recent years, the needs of the users have not been stable. This is due to the nature of the programme, and because cohesiveness and bonding with the entity as a whole have been conspicuous by their absence, but users have engaged in activities which have required continuous participation. Other expressions have been recorded concerning the decline in participation for reasons such as the lack of role models in the team of instructors, the need for the programme to keep reinventing itself in the light of the users' needs, which are ever changing as the young people get older and the group is dismembered.

As regards networking in the Raval neighbourhood, the facilitators have seen the experiences mentioned as positive and enriching, especially in that they provide opportunities for sharing, creating resources, discussing different cases, joining forces to set up sporting, social and cultural events (Neighbourhood Festival, Sant Jordi, Open Raval, Values League ...), and participating, as an entity, in a range of networks: the youth association, the reading network, the Raval Itaca project.

As regards social development and citizen participation, they have perceived certain experiences of aesthetic quality in relation to building bridges between entities and associations in the Raval neighbourhood, which they consider to be very positive for development of a community spirit, whether in the organisation of events, in sharing resources or in staging a public protest for some reason or other. What is more, they have experiences relating to the increase in participation and the beginning a change in the neighbourhood towards a community-oriented vision, a change which is also facilitated with the help and support offered by the different entities. "Community work is this: it is working for the good of all, whether making use of resources made available by the City Council, or through a non-profit organisation, or neighbours' association" (Facilitator 1) Even so, experiences are also expressed relating to factors which hamper development, such as young people leaving for other countries, and the shortage of resources. As regards the development and evolution of the entities, this group focuses his attention only on the TEB and the programmes it organises, thus, as regards affiliation and the sense of belonging to this entity, two of them mention positive experience in relation to affiliation to the entity, and the consequences that flow from feeling that you are part of it: more participation, more success in the projects. As regards the development of the omnia point, the three key informers perceive experiences which are, for the most part, positive, as it is an autonomous programme linking technology with social life, and helps to establish contact with the participants. That said, there is one experience which stresses the fact that there could have been more development, and there are others which, albeit not referring specifically to this omnia point, highlight the need on the part of the team of instructors to keep innovating in the activities they organise, and to take full advantage of the technological elements that might arise out of a given activity. Furthermore, one of the facilitators refers to interesting experiences in 
relation to the evolution of the TEB in recent years: the way it works, its projects, the need to be affiliated to it as an entity, rather than only to the specific activities it organises.

\subsubsection{Users}

The users perceive experiences in which the TEB promotes integrated personal development, especially with regard to the question of values, respect, conflict resolution, self-control and social relationships (trust), to the point of saying, in two cases, that they would not have become the people they are had they not been associated with the entity. All of them also refer to the willingness of the instructors to stimulate them and help them with personal and social issues, and in the pursuit of interests such as dancing (break dance) and music (rap).

With regard to the relationships that are established among them, they perceive experiences of aesthetic quality when the relationships are strong, to the point where the others become "your group of friends" (User 1). Even though they also relate to participants in other entities, these relationships cannot be compared with the bond that is formed when they share activities with other users of the TEB, because, though they do not know all the users, they feel positive about the experiences when all the participants are enjoying each other's company: "We are very united. When we joined some of us knew each other, others didn't, but we realised at once that we would get on well, no problems." (User 2). With regard to the relationships with the facilitators, all the users perceive experiences in which the latter are regarded as understanding and empathising with them, so the relationships are perceived as personal and informal, as there is an underlying trust, and the instructors offer help and support, and they can count on them. As far as participation in the entity is concerned, there are some experiences in which there are perceived to be ups and downs: that is to say, there is always someone who does not come regularly, but the participation of the informers is continuous and regular, though it depends on their availability. Besides, all of them participate or have participated in other recreational entities, and in some cases they have ceased to be involved in the other entities when they joined the TEB.

In relation to the networking being developed in the Raval, all the experiences expressed reflect a positive perception of the fact of sharing with other members of the community, and finding solutions together. They mention, by way of example, the concerts that are co-organised by all the entities and social institutions, and the main annual festival. Likewise, all the users perceive the social development and citizen participation as positive experiences, in that they have brought benefits to the community through collective protests and demonstrations against the action taken by the public institutions, or events centring around a tragic incident, such as the death of a resident of the neighbourhood at the hands of the regional police force, to name just one of the best-known incidents. In this case the event consisted of composing a song together which they called, "fighting our rights". In addition, they all perceive experiences of aesthetic quality in the most dramatic moments, as that is when the pride in belonging to this historic, intercultural neighbourhood, despite the fact that, as so many cultures are living together, there are negative prejudices at work in this development, and also a diversity of opinions, as is reflected in the experiences of one user. Even so, there are experiences relating to the indispensable nature of the intervention by the 
social entities in the neighbourhood, in that they create bonds, they keep the community informed and unify it. In terms of the development of neighbourhood entities, many of the experiences recorded have to do with affiliation to the TEB, and the sense of belonging to an entity, and strengthen the bond with the entity and promote participation.

\subsubsection{Residents of the neighbourhood}

Finally, the last group of key informers to express their experiences of aesthetic quality when they reflect the fact that the TEB is an educational space to meet, to grow as people, where there is a good relationship with the agents involved in the socio-educational project, who help them to reflect and accompany them on their journey into the adult world.

As regards the relationships which take place in the TEB, some experiences point to the good relationship between the participants in the mediatheque and the facilitator, as they help each other, share and gradually build a mutual trust. Likewise, certain experiences are expressed concerning the relationships between other entities and the TEB, how bridges are built among these entities through the personal relationships with participants, and the informers' own relationships with many other neighbourhood entities, which is regarded as something very positive, a source of personal enrichment, a visible feature of the neighbourhood and means of bonding with others. As far as participation is concerned, they are involved in many neighbourhood entities. As their involvement is continuous and regular, they all see this constant participation as an occupation, a means of feeling useful. "I prefer being in the Casal, when I'm there I feel useful to others" (Neighbourhood resident 3). They participate and cooperate in different entities like the Taradelles, the Trueta, the Asociación de la calle de la cera and the Women's association.

As for networking in the neighbourhood, there are different perceptions, as all the informers mention the work they do jointly in the neighbourhood in staging sociocultural music or theatre events, but in terms of becoming more acquainted with the network and how it works, one of the informers sees her experience in a broader sense as she is involved in a number of different entities, as well as some communication and coordination tables Thus, although the action of the network and the fact of sharing are seen in positive terms, there is also a perception that there is a lack of common aims between the different entities, associations and institutions in the neighbourhood.

Among their experiences of aesthetic quality, they mention the fact that immersion in the world of social entities has been life-changing in the way they see others: they say that they are more inclined to help, and are closer to people, even though they still see examples of self-centredness. There are interesting experiences of mutual help and enrichment between people and entities in the neighbourhood, whether in setting up or holding an event, given the massive influx of immigrants, aimed at compiling the history of the neighbourhood and its inhabitants. But one of the informers also stressed the need for people to come together and fight for the interests of the neighbourhood, not only for one's own personal interests, as the action of the government reflects no respect for the neighbourhood, nor interest in preserving it. As regards the development of the social entities of the neighbourhood, there is one experience which highlights the associative fabric of the Raval resulting from the influx of 
immigrants. There are also two experiences concerning the TEB and the work being done in the neighbourhood, stressing the fact that it is close to young people, and another relating to the collaboration between the entities in the neighbourhood, the work they do, the groups of people they are made up of and the aims they are pursuing.

\section{Conclusions}

The social e-learning programme under consideration in this study is made possible by the technological features of the entity in which it was carried out, one of the pioneer entities in Catalonia in consolidating e-learning and making it a natural means of providing the training required for life. At the same time, this training-oriented space has given rise to deep and deeply-rooted human relationships which are of enormous benefit to the entity and the community, and conducive to their development. A clear example of this are the experiences of aesthetic quality in which the key informers consulted concur that these experiences are positive in that they promote learning and bonding with the entity and the community.

"Yes there is bond between us (...) We got to know each other here, and we played together and chatted, and became friends" (User 1) "We are all from different places and we are all very united" (User 2) "It's like talking to our friends (with the instructors) and they understand you and explain things to you, they give you their opinion and they make you think" (User 3).

"It's a work space where we are very close to the users ... because we are very natural, and we always tell them about how we feel" (Facilitator 3) "They come here because they meet up with others every week, and they stand around the door chatting" (Facilitator 2).

"And they treat us very well. They have a place where they meet and grow as people... they have young people who are instructors, but they are also role models. If anything happens to them, if they have a problem, or whatever, they can tell the instructor, and he or she helps them, if they have to process a job application, deal with documents, they will help them to sort that out." (Neighbourhood resident 1)

There is also a lot of agreement regarding community development and networking, as all the key informers express experiences relating to the activities carried out by all the entities in the Raval to promote bonding with the neighbourhood and its development, in that it empowers the inhabitants, as they are the people who extend neighbourhood networking by building bridges with other entities.

"For the main local festival or Sant Jordi they organise joint activities, the older ladies with the local young people who started singing Rap and we (the older ladies) were afraid of this Rap stuff, it was hard to get used to the idea, but they wrote a song and then we did a verse, and then they sang the song and we added our verse and we put on caps and danced like them; in that way things really go well." (Neighbourhood resident 1)

From the data obtained in the study and the way in which it was conducted, we can confidently confirm the huge influence of the "Omnia Point" social e-learning programme 
and of all the specific activities that it comprises, which play a crucial role in the in the perception and generation of social experiences of aesthetic quality (both individual and collective) among the three groups interviewed. Despite the fact that the expressions of these experiences are not very concrete, and reflect general perceptions, they are experiences of aesthetic quality in themselves, in the way in which they have influenced (and continue to influence) the people who give expression to them, thus triggering personal development, as well as constructive learning. This is clearly reflected throughout the experiences under consideration.

\section{References}

Abbs, P. (1989). A is for aesthetic (1st ed.). Falmer Press. NY.

Bliss, L. (2016). Phenomenological Research: Inquiry to Understand the Meanings of People's Experiences. International Journal of Adult Vocational Education and Technology, 7(3). http://dx.doi.org/10.4018/IJAVET.2016070102

Cilesiz, S. (2011). A phenomenological approach to experiences with technology: current state, promise, and future directions for research. Education Tech Research Dev, 59, 487-510. http://dx.doi.org/10.1007/s11423-010-9173-2

Clover, D., Sanford, K., \& Butterwick, S. (2013). Aesthetic practices and adult education. London. UK: Routledge

Dewey, J. (1934). Art as Experience. Nueva York, EE.UU.: Berkley Publishing Group (Penguin).

Diessner, R., Kirk, C., Guenthner, C., Pohling, R., \& Mobasher, S. (2016). Teaching the Psychology of Engagement with Beauty: State and Trait. Teaching of Psychology, 44(1), 63-67. http://dx.doi.org/10.1177/0098628316679969

Friedman, M., Beckwith, R. M., \& Conroy, J. (2016). Effective Strategies for Supporting Individuals With Complex Needs in Leadership Roles. Inclusion, 4(3), 170-182. http://dx.doi.org/10.1352/2326-6988-4.3.170

Greene, M. (1995). Releasing the imagination (1st ed.). San Francisco: Jossey-Bass Publishers.

González, J. C. (2006). Perspectivas contemporáneas sobre la cognición: categorización, percepción y conceptualización. Méjico: Siglo XXI (Universidad Autónoma del Estado de Morelos).

Kholina, A. (2015). Aesthetic responses made visible through voices of experts. Journal of Research Pratice, 11(2).

Marín, R. (1985). “El muestreo”. Tema 6. En Marín Ibáñez y Pérez Serrano, G.: Pedagogía Social y Sociología de la Educación. Unidades Didácticas 1, 2 y 3. Madrid, España: UNED, 161-186.

Mays, N., \& Pope, C. (1995). Qualitative Research: Observational methods in health care 
settings. BMJ, 311(6998), 182-184. http://dx.doi.org/10.1136/bmj.311.6998.182

Morgan, S., Pullon, S., Macdonald, L., McKinlay, E., \& Gray, B. (2016). Case Study Observational Research: A Framework for Conducting Case Study Research Where Observation Data Are the Focus. Qualitative Health Research. http://dx.doi.org/10.1177/1049732316649160

Morse, J. (2003). Perspectives of the Observer and the Observed. Qualitative Health Research, 13(2), 155-157. http://dx.doi.org/10.1177/1049732302239595

Mulhall, A. (2003). In the field: notes on observation in qualitative research. Journal of Advanced Nursing, 41(3), 306-313. http://dx.doi.org/10.1046/j.1365-2648.2003.02514.x

Obando, C. (2007). Las TIC: un nuevo escenario para el desarrollo local de las comunidades (Estudio de Caso: Comunidad Ómnia-Barrio el Raval, Barcelona). Ph.D. Thesis. Universidad Pompeu Fabra.

Osterlind, S. J. (1989). Constructing test items. Londres, Inglaterra: Kluwer Academic Publishers.

Patton, M., (2015). Qualitative research \& evaluation methods: Integrating theory and practice (4th ed.). Thousand Oaks, CA: Sage.

Readman, K., \& Wise, J., (2004). Aesthetic pedagogy and digital resource design: some considerations. Change: Transformations in Education. Vol 7.2, November.

Rodríguez, R. (2004). ¿Kant o Nietzsche? ¡Dewey! El idealismo naturalista y democrático del arte como experiencia. Fedro, revista de estética y teoría de las artes, (2), 51-69.

Savva, N., Scarinzi, A., \& Bianchi-Berthouze, N., (2012). Continuous recognition of player's affective body expression as dynamic quality of Aesthetic Experience. IEEE. Transactions on computational intelligence and AI in games, 4(3). http://dx.doi.org/10.1109/TCIAIG.2012.22002663

Saldaña, J. (2013). The coding manual for qualitative researchers (1st ed.). Los Angeles [i.e. Thousand Oaks, Calif]: SAGE Publications.

Silverman, D. (1993). Interpreting Qualitative Data. Londres, Inglaterra: Sage Publication.

Smith, K., (2016). A phenomenological study of aesthetic experience within an arts council's events and programs: finding joy, expression, connection and public good in the arts. $\mathrm{PhD}$ Thesis. Miami University.

Wolcott, H. F. (1994). Transforming qualitative data: Description, analysis, and interpretation. Thousand Oaks, California: Sage Publications, Inc.

Yin, R., (2014). Case Study Research Design and Methods (5th ed.) Thousand Oaks, CA: Sage. 
Notes

Note 1. Training programme in technological and digital competence, dependent on and subsidised by the Generalitat of Catalonia. It is offered in many of the community's institutions and social entities.

Note 2. An acronym of the name "The Ecological Boys", a project created for and by the young people of the street in which they organised many excursions in the mountains, hence the name.

Note 3. A capacity which an agent possesses (an individual or an entity) to act in the world, but not any capacity for action or for the exercise of power, but one which enables the subject to act on the structure which is also, as he or she knows, is also acting on them.

\section{Copyright Disclaimer}

Copyright reserved by the authors.

This article is an open-access article distributed under the terms and conditions of the Creative Commons Attribution license (http://creativecommons.org/licenses/by/3.0/). 